\title{
Trasplante pulmonar
}

\section{Lung transplantation}

Desde hace 30 años que el trasplante pulmonar ha evolucionado desde lo anecdótico y excepcional a una terapia esperada y habitual para un grupo de pacientes portadores de enfermedad pulmonar avanzada refractaria a tratamiento médico. Se inició como técnica cardiopulmonar en 1981, monopulmonar en 1983 y luego bilateral secuencial desde 1985. En nuestro país el trasplante pulmonar se inició en el año 1999 y en la actualidad se realiza en el área pública y privada.

En relación a otros trasplantes de órgano sólido, la técnica pulmonar presenta características que han dificultado su desarrollo, es así como la conexión al ambiente a través de la vía aérea lo expone a irritantes, infecciones y estímulos antigénicos que estimulan la alorreactividad del receptor y el riesgo de rechazo del injerto.

La mejoría de los protocolos de inmunosupresión y de profilaxis infecciosa han llevado al aumento sostenido en el número de trasplantes por año y de acuerdo a los registros de ISHLT (International Society of Heart and Lung Transplantation) alcanzaron a 3.893 procedimientos el año 2013, con un predominio de la técnica bipulmonar.

La sobrevida a 1 y 5 años también ha experimentado una mejoría, ya que en 1994 era de 70 y 49\%, en tanto que en 2010 alcanzó a 80 y 54\% respectivamente. La mejoría de este procedimiento es multifactorial destacando las soluciones de preservación del órgano, la técnica de anastomosis bronquial, la introducción de inmunosupresores más selectivos, los criterios de selección del donante y del receptor y el aporte de las técnicas de circulación extracorpórea a la disfunción primaria de injerto (DPI).

Otro factor determinante ha sido la asignación de puntajes de urgencia en lista de espera a un grupo de pacientes, conocido como LAS (Lung Allocattion Score) ${ }^{1}$ en uso en Estados Unidos desde el año 2005, lo que favorece a portadores de Fibrosis pulmonar, quienes experimentaban la mayor tasa de mortalidad previo a la cirugía. En nuestro país la selección de urgencia se realiza desde el año 2012 y se basa en requerimientos de ventilación mecánica no invasiva o necesidad de soporte extracorpóreo².

La derivación oportuna a un centro de trasplante y la selección del probable candidato, se realiza de acuerdo a guías internacionales recién actualizadas ${ }^{3}$, las que rigen en nuestro país. En los registros nacionales la mayor indicación la constituyen los pacientes portadores de enfermedad intersticial pulmonar ${ }^{4}$ y existe un número creciente de pacientes con Fibrosis quística.

El trasplante pulmonar se asocia a una notable mejoría de la calidad de vida en pacientes con severa patología respiratoria. Sin embargo, el gran desafio en la actualidad lo constituye el manejo del rechazo crónico conocido principalmente como Síndrome de Bronquiolitis Obliterante ${ }^{5}$ el cual es responsable del $50 \%$ de la mortalidad tardía.

El resultado óptimo depende de una derivación precoz, adecuada selección del candidato 6 y evitar el daño progresivo de otros órganos que llegue a contraindicar el procedimiento del trasplante.

Dra. María Teresa Parada C.

Coordinadora Programa Trasplante Pulmonar

Clínica Las Condes

Email:mtparada@clc.cl 


\section{Bibliografía}

1.- MERLO C A, WEISS E S, ORENS J B, BORJA M C, DIENER-WEST M, CONTE J V, et al. Impact of U.S. Lung Allocation Score on survival after lung transplantation. J Heart Lung Transplant 2009; 28: 769-75.

2.- MELO J, PARADA M T, SEPÚLVEDA C, LINACRE $\mathrm{V}$, SALINAS M, LAZO D, et al. Resultados del trasplante pulmonar en pacientes en situación de urgencia. Rev Chil Enferm Respir 2015; 31: 195-200.

3.- WEILL D, BENDEN C, CORRIS P A, DARK J H, DAVIS R D, KESHAVJEE S, et al. A consensus document for the selection of lung transplant candidates: 2014 an update from the Pulmonary Transplantation
Council of the International Society for Heart and Lung Transplantation. J Heart Lung Transplant 2015; 34: 1-15.

4.- PARADA M T, MELO J, SEPÚLVEDA C, LAZO D, LINACRE V, VILLALABEITIA E, et al. Trasplante pulmonar en pacientes portadores de fibrosis pulmonar: cohorte de 87 pacientes. Rev Chil Enferm Respir 2015; 31: 189-94.

5.- PARADA M T, ALBA A, SEPÚLVEDA C. Bronchiolitis obliterans syndrome development in lung transplant patients. Transplant Proc 2010; 42: 331-2.

6.- PARADA M T, SEPÚLVEDA C. Indicaciones de trasplante pulmonar según patología de base. Rev Chil Enferm Respir 2015; 31: 207-11. 